\title{
Biochemical Markers in COVID-19 in Multan
}

\author{
Waqas Hanif, Oshaque Ali, Haseeba Shahzad, Muhammad Younas, Hamid Iqbal and Kamran Afzal \\ Department of Pathology, Combined Military Hospital, Multan, Pakistan
}

\begin{abstract}
Objective: To determine clinical features and biochemical markers in COVID-19 patients at a tertiary care hospital, in Multan. Study Design: Descriptive cross-sectional study.

Place and Duration of Study: Department of Pathology, Combined Military Hospital, Multan, Pakistan, from March to June 2020.

Methodology: Sixty-three cases of all ages admitted in Isolation ward, Combined Military Hospital, Multan with COVID-19 were included. Clinical features like fever, cough and shortness of breath were recorded. Blood sample was collected in plain tube for biochemical features like serum albumin, ferritin, AST, LDH, CRP and urea, which were analysed in Pathology Department of the Hospital. Association of the clinical features and these biochemical markers were determined.

Results: In 63 patients, only one (1.6\%) patient was between 1 to 12 years, $42(66.7 \%)$ belonged to 13 to 45 years while 20 (31.7\%) patients were between 46 to 95 years. Mean age was $41.39 \pm 15.68$ years. Forty-eight $(76.2 \%)$ patients were males and $15(23.8 \%)$ females. Thirteen (20.6\%) patients presented with fever, $14(22.2 \%)$ had productive cough and only $3(4.8 \%)$ patients were aware of known history of contact. Median (IQR) value of serum ferritin, LDH, albumin, AST, CRP and urea were 176.5 (252) ng/ml, 284 (96) IU/L, 42 (7) g/L, 28 (22) U/L, 3.9 (11) mg/L and 4.25 (1.6) mmol/L, respectively.

Conclusion: Pakistani patients with COVID-19 disease showed variable pattern of clinical features. Specific biochemical markers, particularly serum ferritin, may help in diagnosis.
\end{abstract}

Key Words: Covid-19, Clinical features, Biochemical features, Multan, Pakistan.

How to cite this article: Hanif W, Ali O, Shahzad H, Younas M, Iqbal H, Afzal K. Biochemical Markers in COVID-19 in Multan. J Coll Physicians Surg Pak 2020; 30(10):1026-1029.

\section{INTRODUCTION}

An outbreak caused by a viral pathogen, leading to respiratory disease had occurred in December 2019 in Wuhan, China, linked to the wet animal market. ${ }^{1}$ Later, corona virus was identified as causative agent which targets the respiratory system of humans. ${ }^{2}$ Then many other countries were involved including United States, Canada, Thailand, Sri Lanka, Japan, Germany, India, France, Cambodia, Singapore, Malaysia, Vietnam, Nepal etc. ${ }^{3}$ The fatality rate was estimated to be 170 out of 7,824. This disease, COVID-19, spread to different continents of this Globe, which compelled WHO to recognise this outbreak as a pandemic, SARS-CoV-2 on $11^{\text {th }}$ March. ${ }^{4}$ In last 20 years, this is the third serious worldwide outbreak. ${ }^{5}$ The common symptoms of this ailment are headache, lymphopenia, diarrhoea, sputum production, dyspnoea and haemoptysis: and is transmitted from person to person through direct contact or via droplets in sneezing or coughing from the diseased person. ${ }^{6}$

Correspondence to: Dr. Waqas Hanif, Department of Pathology, Combined Military Hospital, Multan, Pakistan E-mail:drwaqas10@yahoo.com

Received: July 07, 2020; Revised: September 26, 2020;

Accepted: October 17, 2020

DOI: https://doi.org/10.29271/jcpsp.2020.10.1026
SARS-COV-2 belongs to enveloped viral family with large diversity, single stranded RNA and positive sense which infects both animals and human leading to gastrointestinal, hepatic and respiratory diseases. ${ }^{7}$ COVID-19 belongs to seventh member of the family of coronaviruses with subfamily ortho-coronavirinae. ${ }^{8}$ SARS-Cov-2 has $96 \%$ similar genetically with Bat CoV RaTG13. A bat corona virus leading to the believe that this virus originated from bat but transmitted directly or by a vector, still to be determined. ${ }^{9}$

In order to prevent this illness, strict preventive measures have been recommended to follow, including refrain from public transport, avoid contact with sick people, avoid crowds, unnecessary travel and most importantly maintain good personal as well as social hygiene. ${ }^{10}$ Pakistan is also one of those countries which is victim to COVID 19. In Pakistan, 192,970 suspected individuals were reported till $25^{\text {th }}$ June 2020 . This study was planned to observe clinical features and biochemical markers, which were affected in COVID-19 positive patients.

\section{METHODOLOGY}

This cross-sectional, observational study was conducted at Combined Military Hospital, Multan from March to June 2020. Approval from Institutional Ethical Committee was taken for this study. Informed written consent was sought from all the participants of this study. 
Table I: Biochemical markers with median with inter-quartile range.

\begin{tabular}{|l|c|c|c|}
\hline Biochemical markers with reference interval & Median (IQR) & $\begin{array}{c}\text { Correlation } \\
\text { r-value }\end{array}$ & A-value in years \pm SD \\
\hline Serum Ferritin (ng/ml) (15-35) & $176.5(252)$ & 0.341 & 0.006 \\
\hline Serum Albumin (g/dl) (35-50) & $42(7)$ & -0.073 & 0.570 \\
\hline Serum LDH (IU/L) (140-280) & $284(96)$ & 0.131 & 0.308 \\
& & & $41.39 \pm 15.68$ \\
\hline Serum AST (IU/L) (6-34) & $28(22)$ & -0.031 & 0.812 \\
\hline Serum Urea (mmol/L) (2.8-7.4) & $4.25(1.6)$ & 0.179 & 0.160 \\
\hline Serum CRP (mg/L) (0-6) & $3.9(11)$ & 0.235 & 0.064 \\
\hline
\end{tabular}

A sample size of 63 was calculated considering a confidence level of $95 \%$, proportion of cases as $70.5 \%$ and $5 \%$ margin of error. Study participants comprised of cases of both genders of all ages, having PCR positive for COVID-19 (continuously detectable COVID RNA on qualitative polymerase chain reaction), having different comorbidities and willing to be part of this research. Patients having negative PCR for COVID-19 were excluded.

After taking relevant history, like cough, fever and history of contact and physical examination, like temperature and respiratory rate, venous blood sample of each patient was taken and sent in plain tube and ABGs sample in heparinised syringe to institutional laboratory for analysis of serum ferritin, LDH, albumin, AST, urea, and CRP. A specialised proforma was designed to record all the study information.

SPSS version 21.0 was used for data analysis. Normality test i.e., one-sample Kolmogorov-Smirnov test between PCR for COVID-19 and different biochemical markers, was applied which showed $p$-value $<0.05$, indicating data was non-parametric. Mean and standard deviation was estimated regarding age, while median (IQR) for ferritin, LDH, albumin, AST, CRP and urea levels. Presence of malarial parasites was also noted. One-sample Chi-square test was applied to compare qualitative variables considering $p$-value less than 0.05 as statistically significant. Spearman's correlation was also applied and $p$-value $<0.05$ considered as statistically significant

\section{RESULT}

Sixty-three patients, who met the inclusion criteria of different ages, were included in this study. Patients were divided into 3 groups according to different ages. Only one (1.6\%) patient was between 1 to 12 years, $42(66.7 \%)$ belonged to 13 to 45 years, while $20(31.7 \%)$ patients were between 46 to 95 years. Mean age of patients was $41.39 \pm 15.68$ years. Forty-eight $(76.2 \%)$ patients were males and $15(23.8 \%)$ were females. No malarial parasite was seen.

Thirteen (20.6\%) patients were presented with history of fever, while 50 (79.4\%) had no fever. Out of 63,14 (22.2\%) has productive cough and $49(77.8 \%)$ were presented without cough. It was very strange that only $3(4.8 \%)$ patients were aware of history of contact, while remaining $95 \%$ were unaware of contact. Almost $6(9.5 \%)$ had different comorbidities and $3(4.8 \%)$ presented with acid base disorder.

Median with IQR value of serum ferritin, LDH, albumin, AST, CRP and urea were 176.5 (252) ng/ml, 284 (96) IU/L, 42 (7) $\mathrm{g} / \mathrm{L}, 28$ (22) U/L, 3.9 (11) mg/L and 4.25 (1.6) mmol/L, respectively. Serum ferritin ranges from 31.60 to $6319 \mathrm{ng} / \mathrm{ml}$, LDH from 224 to $3332 \mathrm{IU} / \mathrm{L}$, albumin 20 to $50 \mathrm{~g} / \mathrm{dl}$, AST from 11 to $218 \mathrm{IU} / \mathrm{L}, \mathrm{CRP}$ from 0.18 to $596.6 \mathrm{mg} / \mathrm{L}$ and urea from 2.3 to $23 \mathrm{mmol} / \mathrm{L}$, respectively (Table I). Out of 63 patients, 15 (23.8\%) have ferritin level $>336 \mathrm{ng} / \mathrm{ml}$ (upper reference limit). $6(9.5 \%)$ patients have LDH level > than $480 \mathrm{IU} / \mathrm{L}$ (upper reference limit), 2 (3.2\%) patients have albumin level $<$ than $35 \mathrm{~g} / \mathrm{dl}$ (lower reference limit), 4 (6.3\%) patients have AST level >40 IU/L (upper reference limit), 16 (25.4\%) patients have CRP level $>10$ (upper reference limit) and 5 $(7.9 \%)$ have urea level $>8.3 \mathrm{mmol} / \mathrm{L}$ (upper reference limit).

Spearman's correlation between PCR and different biochemical markers also showed $p$-value $<0.05$. Chi-square correlation between PCR and clinical features, and PCR and biochemical markers were applied, which also showed $p$ value of $<0.05$.

\section{DISCUSSION}

SARS is an infectious disease in which various parts of the body get effected. Some of the complications included are coagulopathy, pneumonia, myositis, kidney and liver dysfunctioning and lymphopenia. ${ }^{11}$ The level of C-reactive protein (CRP) can be used for diagnosis of pneumonia in early stages, ${ }^{12}$ and increased CRP level can be noted with the increase of severity of SARS Corona virus disease.

It has also been observed in study that there is positive correlation between CRP levels and lung lesion diameter. ${ }^{13}$ Besides abnormal blood coagulation functioning, the elevation of C-reactive protein is crucial inflammatory index. ${ }^{14}$ Increased CRP level in patients suffering from coronavirus disease has been observed in many other studies. ${ }^{15}$ Increased in level of lactate dehydrogenase and aspartate transferase, which are associated with myocardial injury, has also been observed in previous studies. ${ }^{16}$ Increased aspartate transferase is also associated with liver dysfunctioning; and its elevated level 
has been noticed in patients with non-severe coronavirus disease. ${ }^{17}$ In addition to that, increased ferritin level has been also observed in coronavirus patients in previous studies. ${ }^{18}$ According to study in China on 191 patients suffering from COVID-19, non-survivors were observed more often with elevated level of LDH and ferritin levels as compared to survivors. ${ }^{19}$ Similarly, in another study conducted in China on 150 patients suffering from COVID19, the elevated level of ferritin (in non-survivors verses survivors were found 1297.6 $\mathrm{ng} / \mathrm{ml}$ and $614.0 \mathrm{ng} / \mathrm{ml}$, respectively). Increased level of serum ferritin is found to be associated with ARDS development, as shown by Wu et al. ${ }^{20}$ Decreased in level of albumin which is also associated with liver injury, has also been noticed in coronavirus patients in previous studies. ${ }^{21}$ In nutritional status, albumin is most instinctive index of our body. Decreased level of albumin is associated with less resistance of body against virus, which leads to progression of disease. ${ }^{22}$ Elevated level of serum creatinine and blood urea nitrogen, which are associated with damage of kidney, has also been observed in previous studies. ${ }^{23}$

In another study conducted on 249 patients with median age 51 years, the most common symptoms at the start of coronavirus disease were fever $(87.1 \%)$, fatigue $(15.7 \%)$ and cough (36.5\%). Similarly, in another study conducted on coronavirus patients, $73.1 \%$ people got treatment for fever. ${ }^{24}$ In $39.7 \%$ patients, $37.3-38.0^{\circ} \mathrm{C}$ was the maximum body temperature that was observed. At admission the body temperature remains significantly higher in older people than younger one $\left(38.2^{\circ}\right.$ vs. $\left.37.5^{\circ} \mathrm{C}\right)$.

The main limitation of this study is cross-sectional design and single-centre research carried out at Pathology Department. Extensive clinical features, including oxygen saturation levels and complete clinical profile, need to be studied with a multidisciplinary approach.

\section{CONCLUSION}

COVID-19 positive patients showed particular pattern of clinical features and biochemical markers, which may facilitate diagnosis of COVID-19 infection. A multicenter study with large population size should be performed to establish relationship between COVID-19 PCR positive and clinical / biochemical features.

\section{ETHICAL APPROVAL:}

Approval from Institutional Ethical Committee was taken for this study from Ethical Committee, Combined Military Hospital, Multan.

\section{PATIENTS' CONSENT:}

Informed written consents were obtained from all the participants of this study.

\section{CONFLICT OF INTEREST:}

There is no conflict of interest.

\section{AUTHORS' CONTRIBUTION:}

WH: Data acquisition and analysis, interpretation, and final approval.

OA: Conception and design, interpretation, critical revision, and final approval.

HS: Design, critical revision, and final approval.

MY: Interpretation, critical revision, and final approval.

$\mathrm{HI}$ : Interpretation, critical revision, and final approval.

KA: Analysis and interpretation, drafting, and final approval.

\section{REFERENCES}

1. Higgins JP, Thompson SG, Deeks JJ, Altman DG. Measuring inconsistency in meta-analyses. $\mathrm{Br}$ Med J 2003; 327 (7414):557-60. doi: 10.1136/bmj.327.7414.557.

2. Chen L, Liu HG, Liu W, Liu J, Liu K, Shang J, et al. [Analysis of clinical features of 29 patients with 2019 novel coronavirus pneumonia]. Zhonghua Jie He He Hu Xi Za Zhi 2020; 43(3):E005. doi: 10.3760/cma.j.issn.1001-0939. 2020. 03.013.

3. Chen C, Chen C, Jiangtao Y, Ning Z, Jianping Z, Daowen W. Analysis of myocardial injury in patients with COVID-19 and association between concomitant cardiovascular diseases and severity of COVID-19. Chin J Cardiol 2020; 48(7):E008. doi: 10.3760/cma.j.cn112148-20200225-00123.

4. Fan BE, Chong VC, Chan SS, Lim GH, Lim KG, Tan GB, et al. Hematologic parameters in patients with COVID-19 infection. Am J Hematol 2020; 95(6):E131-4. doi: 10.1002/ajh. 25774 .

5. Guan WJ, Ni ZY, Hu Y, Liang WH, Ou CQ, He JX, et al. Clinical characteristics of coronavirus disease 2019 in China. N Engl J Med 2020; 382:1708-1720. doi: 10.1056/ NEJMoa 2002032.

6. Huang C, Wang Y, Li X, Ren L, Zhao J, Hu Y, et al. Clinical features of patients infected with 2019 novel coronavirus in Wuhan, China. Lancet 2020; 395(10223):497-506. doi: 10.1016/S0140-6736(20)30183-5.

7. Liu Y, Yang Y, Zhang C, Huang F, Wang F, Yuan J, et al. Clinical and biochemical indexes from 2019-nCoV infected patients linked to viral loads and lung injury. Sci China Life Sci 2020; 63(3):364-74. doi: 10.1007/s11427-020-1643-8.

8. Liu W, Tao Z-W, Lei W, Ming-Li Y, Kui L, Ling Z, et al. Analysis of factors associated with disease outcomes in hospitalized patients with 2019 novel coronavirus disease. Chin Med J 2020; 133(9):1032-8. doi: 10.1097/CM9. 0000000 000000775.

9. Qin C, Zhou L, Hu Z, Zhang S, Yang S, Tao Y, et al. Dysregulation of immune response in patients with COVID-19 in Wuhan, China. Clin Infect Dis 2020; 71(15):762-8. doi: 10.1093/cid/ciaa248.

10. Ruan Q, Yang K, Wang W, Jiang L, Song J. Clinical predictors of mortality due to COVID-19 based on an analysis of data of 150 patients from Wuhan, China. Intensive Care Med 2020; 46(5):846-8. doi: 10.1007/s00134-020-05991$\mathrm{x}$.

11. Qu R, Ling Y, Zhang YH, Wei LY, Chen X, Li X, et al. Platelet-to-lymphocyte ratio is associated with prognosis in patients with Corona Virus Disease-19. J Med Virol 
2020; 10:1002/jmv.25767. doi: 10.1002/jmv.25767.

12. Liu M, He P, Liu M, Wang X, Li F, Chen S, et al. [Analysis of clinical characteristics of 30 cases of new coronavirus pneumonia in medical staff]. Chin J Tuberculosis Respir Dis 2020; 43:209-14.

13. Qian GQ, Yang NB, Ding F, Ma AH, Wang ZY, Shen YF, et al. Epidemiologic and clinical characteristics of 91 hospitalized patients with COVID-19 in Zhejiang, China: A retrospective, multi-centre case series. Q J Med 2020; 113(7):477-81 doi: 10.1093/qjmed/hcaa089.

14. Tianxin X, Liu J, Xu F, Cheng N, Liu Y, Qian K. [Analysis of clinical features of 49 patients with new type of coronavirus pneumonia in Jiangxi]. Chin J Respir Crit Care 2020.

15. Wang D, Hu B, Hu C, Zhu F, Liu X, Zhang J, et al. Clinical characteristics of 138 hospitalised patients with 2019 novel coronavirus-infected pneumonia in Wuhan, China. J Am Med Assoc 2020; 323(11):1061-9. doi: 10.1001/jama. 2020.1585.

16. Wang Z, Yang B, Li Q, Wen L, Zhang R. Clinical features of 69 cases with coronavirus disease 2019 in Wuhan, China. Clin Infect Dis 2020; 71(15):769-77. doi: 10.1093/ cid/ciaa272.

17. Wu C, Chen X, Cai Y, Xia J, Zhou X, Xu S, et al. Risk factors associated with acute respiratory distress syndrome and death in patients with coronavirus disease 2019 pneumonia in Wuhan, China. JAMA Intern Med 2020; 180(7):934-43. oi: 10.1001/jamainternmed.2020.0994.

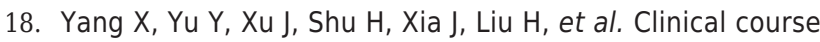
and outcomes of critically ill patients with SARS-CoV-2 pneu- monia in Wuhan, China: A single-centered, retrospective, observational study. Lancet Respir Med 2020; 8(5):475-81. doi: 10.1016/S2213-2600(20)30079-5.

19. Zhou $P$, Yang $X L$, Wang $X G$, Hu B, Zhang $L$, Zhang $W$, et al. A pneumonia outbreak associated with a new coronavirus of probable bat origin. Nature 2020; 579(7798):270-273. doi: 10.1038/s41586-020-2012-7.

20. Liu W, Li H. COVID-19: Attacks the 1-beta chain of hemoglobin and captures the porphyrin to inhibit human heme metabolism. ChemRxiv 2020; 10(04). doi 10.26434/chemrxiv.11938173

21. Young BE, Ong SW, Kalimuddin S, Kalimuddin S, Low JG, Tan $S Y$, et al. Epidemiologic features and clinical course of patients infected with SARS-CoV-2 in Singapore. J Am Med Assoc 2020; 323(15):1488-94. doi: 10.1001/jama.2020. 3204.

22. Meduri GU, Headley S, Kohler G, Stentz F, Tolley E, Umberger $\mathrm{R}$, et al. Persistent elevation of inflammatory cytokines predicts a poor outcome in ARDS. Plasma IL-1 beta and IL- 6 levels are consistent and efficient predictors of outcome over time. Chest 1995; 107(4):1062-73. doi: 10.1378/chest.107.4.1062.

23. World Health Organization-China Joint Mission. Report of the WHO-China Joint Mission on Coronavirus Disease 2019 (COVID-19). Geneva 2020; 9(1):34. doi: 10.1186/ s40249-020-00650-1.

24. Lippi G, Plebani M, Henry BM. Thrombocytopenia is associated with severe coronavirus disease 2019 (COVID-19) infections: A meta-analysis. Clin Chim Acta 2020; 506:145-8. doi: 10.1016/j.cca.2020.03.022. 